\title{
Descripción y narración en las primeras guías turísticas de Navarra (1904-1929)
}

\author{
María Cristina Bordonaba Zabalza ${ }^{i}$
}

Univesità degli Studi di Milano (Italia)

\begin{abstract}
Resumen: con el presente trabajo nos proponemos analizar cuatro guías turísticas de Navarra del periodo comprendido entre 1904-1929. En el análisis textual se observan las simetrías y disimetrías que presenta la macroestructura, así como las estrategias discursivas y léxicas que intervienen en la función persuasiva. Desde un enfoque comparatista, el cotejo de las guías conduce a la reflexión lingüística e ideológica - en esta fase de asentamiento del género del turismo guía - sobre el tipo de procedimientos descriptivos que el emisor lleva a cabo para representar la imagen de un lugar, y responder a las expectativas del destinatario. Concordamos con Adam (2006), en que todo procedimiento descriptivo está indisolublemente ligado a un punto de vista $\mathrm{y}$, consecuentemente, al tipo de imagen que el emisor se propone representar.
\end{abstract}

Palabras clave: estrategia discursiva, procedimiento descriptivo, género

Title: Description and narrative construction in tourist guides to Navarra 1904-1929

\begin{abstract}
Navarra written during the period between 1904 and 1929 . The textual analysis shows the similarities and dissimilarities at the macrostructural level and the discursive and lexical strategies that take part in the persuasive function. From a comparative approach, the comparison between the guidebooks offers a linguistic and ideological reflection - in this phase of consolidation of this tourist genre - on the kind of descriptive procedures that the writer performs in order to describe the image of Navarra and fulfill the addressees' expectations. According to Adam (2006), we believe that every descriptive procedure is indissolubly bound to a point of view and, consequently, to the image that the writer aims to depict.
\end{abstract}

Keywords: discursive strategy, descriptive procedure, genre 


\section{Introducción}

Descripción y narración son dos operaciones discursivas estrechamente vinculadas con la guía turística desde su irrupción como género textual del turismo. No en vano las primeras guías turísticas españolas de finales del siglo XIX reciben la denominación de Guía turística históricodescriptiva, con la que el emisor desea destacar los dos procedimientos discursivos que la configuran, esto es, el narrativo y el descriptivo. Para Ruiz Dávila (2000), la descripción es "un saber sobre las palabras, las cosas, los sentimientos y el mundo en general". Más concretamente, Montolío (2002: 44), precisa que "la descripción sirve para representar la realidad circundante por medio del lenguaje", tras de la cual existe un emisor, porque todo procedimiento descriptivo conlleva la expresión de un punto de vista, de un objetivo del discurso (Adam, 2000: 146).

Estos presupuestos pueden aplicarse a un género como la guía textual del turismo que nos ocupa, por cuanto representa, en la clasificación textual de Adam, el modelo de texto descriptivo que podemos calificar como retóricoreferencial, con el que el emisor cumple tres funciones pragmáticas principales (Calvi, 2011: 10):

a) informar, satisfaciendo las necesidades prácticas y cognoscitivas;

b) instruir, guiando los pasos del turista y proporcionándole elementos útiles para la toma de decisiones;

c) y persuadir, tanto en el plano de la acción como más en general en el de las expectativas.

La segunda operación discursiva, objeto de nuestro estudio, que aparece indisolublemente ligada a la descripción, es la narración, cuya función es la caracterización de acciones, sucesos o acontecimientos (imaginarios o verdaderos) que se sitúan en el transcurso del tiempo (Alcaraz Varó / Martínez Linares, 2004). En la guía turística, la descripción de un lugar o paisaje ocupa un puesto predominante, mientras que la narración aparece en el momento en el que el emisor desea contar la historia del mismo. De este modo, se presentan perfectamente entrelazados y la barrera de separación de ambos textos está determinada por el uso de los tiempos verbales: los del pasado para la narración de hechos históricos relacionados con los monumentos o los lugares, y los del presente para la descripción de los mismos.

Asimismo, atendiendo a la clasificación de géneros del turismo propuesta por Calvi (2010), la guía turística pertenece a la categoría de géneros editoriales y constituye un macrogénero por la combinación de géneros, tipologías textuales y estilos que la configuran, y cuyo resultado final es un producto dotado de una identidad propia.

Partiendo de estos presupuestos, nos proponemos analizar un corpus acotado formado por cuatro guías turísticas de Navarra correspondientes a las tres primeras décadas del siglo XX. El interés por estas guías turísticas se justifica porque son representativas de una fase de asentamiento de este género, que oscila entre un modelo de texto histórico-descriptivo, con un fuerte componente cultural, y un modelo de texto descriptivo en el que la información práctica y visual van adquiriendo un papel relevante.

El análisis textual se llevará a cabo en dos fases: en la primera, se observarán las simetrías y disimetrías que presenta la macroestructura, y la diversificación de los contenidos; en la segunda, las estrategias discursivas y léxicas empleadas en las guías, que subyacen a las operaciones discursivas de descripción y narración. Asimismo, desde el punto de vista del léxico, el análisis cuantitativo y, sobre todo cualitativo, de las formas axiológicas representa, por un lado, un punto de reflexión sobre la posible fijación de determinadas unidades fraseológicas que forman parte de la estrategia de persuasión y, por otro, es el instrumento que el emisor posee para ofrecer una determinada visión del mundo y transmitir una determinada concepción del viaje.

\section{El corpus objeto de estudio: contexto histórico}

Con la publicación del Real Decreto de 6 de octubre de 1905, por el que se crea la Comisión Nacional para Fomentar las Excursiones Turísticas y de Recreo del Público Extranjero, se inicia de forma oficial la labor de promoción turística de los atractivos que ofrece el país: topografía, clima y monumentos artísticos, pero sin ocultar el abandono en que se hallan sumidos algunos de ellos, como reflejo del espíritu noventayochista que dominaba la vida pública de entonces. El objetivo es divulgar, en todos sus aspectos, el conocimiento de España, fomentando para ello la publicación de guías, catálogos, anuncios, itinerarios, etc. dentro y fuera del país, ya directamente o contratando, en su totalidad o en parte, este importante servicio (Esteve / Fuentes, 2000: 18-24). Por ello en la década de los veinte, contexto en el que se publican las guías que nos ocupan, se toman medidas para proyectar la imagen de España en el extranjero ${ }^{1}$. Estas condiciones socioculturales determinan el proceso de desarrollo de los diversos géneros turísticos y, en especial, de la guía.

Las primeras guías histórico-descriptivas ${ }^{2}$ que se publican en España siguen la moda literaria preponderante en Europa a mediados del siglo XIX, que hacía de los libros de viajes la lectura favorita de las minorías ilustradas del continente $^{3}$. Fuera de España, el modelo de referencia de guía turística de entonces es la de Baedecker en Alemania (la traducción de la guía España y Portugal data de 1913) y Murray $^{4}$ en Inglaterra. Este nuevo género, la guía, "cumple una función prescriptiva porque informa, prepara, ayuda, aconseja y se coloca en el papel del viajero, conduciéndolo en su idioma y en sintonía con su mentalidad y forma de pensar en el proceso de contacto con lo nuevo y lo diferente"5 (Santulli, 2010). Asimismo, se caracteriza por una serie de rasgos convencionales, de orden lingüístico y discursivo, relacionados con los contextos sociales y comunicativos. Dichos rasgos, que se han ido manteniendo a lo largo del tiempo, comprenden la presentación en forma de libro y la macroestructura organizada en las siguientes partes: 1) introducción geográfica, 2) perspectiva histórica, 3) descripción del legado artístico-monumental y 
4) información práctica con formato y color diferente, que recoge una serie de datos útiles y necesarios para el viajero. En este sentido, el corpus es representativo de estas funciones, y sus diferentes denominaciones son un reflejo del objetivo que se propone el emisor y del tipo de destinatario al que se dirige: Guía del viajero ${ }^{6}$ (1904), Guía del congresista 7 (1920), Guía del turista ${ }^{8}$ (1926), Guía turistica de Navarra ${ }^{9}$ (1929).

\section{Macroestructura de los textos analizados}

Las cuatro guías se presentan en un formato parecido, en forma de cuaderno y, en el caso de la GTN, más bien de libro pequeño y, por tanto, de fácil manejo para el viajero. Salvo en la GC, en todas las demás las fotos en blanco y negro ocupan un lugar relevante ilustrando el texto descriptivo. Atendiendo a la macroestructura de las guías en cuestión, podemos establecer una comparación de los contenidos de las mismas en la tabla siguiente: se desprende de la dedicatoria que contiene: "Á [sic] mi doctísimo amigo Don Ricardo Ascunce y Juvera. Doctor en Medicina y Cirugía"; así como de otras apreciaciones que intercala entre una descripción y otra: "Conserva esta puerta sus antiguas hojas de madera, y en una de ellas un precioso llamador de hierro calado sobre fondo de grana, que admiran los inteligentes" (p. 22). En esta guía no hay un prólogo en el que el autor exprese sus objetivos, como veremos en las posteriores. En estas desaparecen los contenidos de los capítulos III (Instrucción pública), IV (Beneficencia y caridad), VII (Edificios militares) y VIII (Afueras de Pamplona) ${ }^{10}$, ya que no poseen interés artístico y, por consiguiente, no representan un atractivo para el turista. Sin embargo, en la GV dichos capítulos reflejan el contexto sociocultural en el que ha sido redactada la guía y por ello les podemos atribuir un valor testimonial de la mentalidad de la época, ya que a través de ellos el emisor transmite una representación del mundo, tal y como se observa en los siguientes ejemplos:

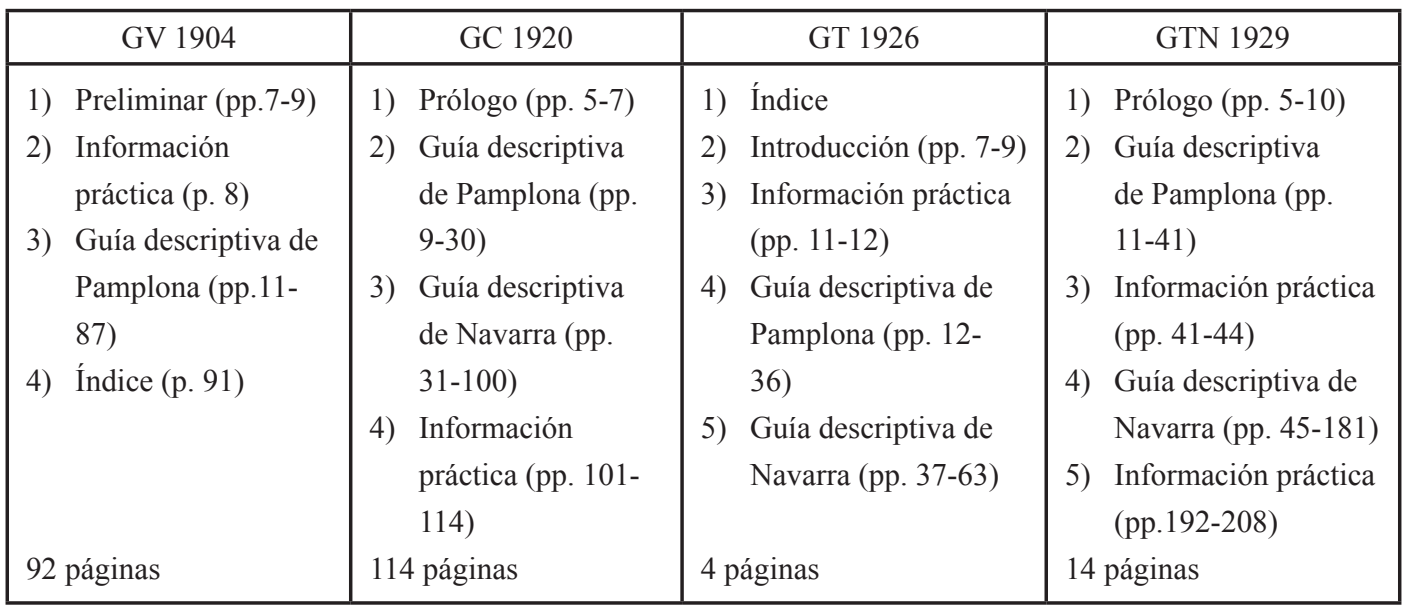

Casa de Señoras Adoratrices. Tienen edificio propio, con iglesia pública, en la calle de la Cuesta del Palacio, frente á [sic] la fachada lateral de la iglesia de San Fermín de Aldapa. Es colegio de jóvenes arrepentidas ó [sic]en peligro de extraviarse (GV, p. 73). Santo Andía. Es una pequeña er-

Para establecer las simetrías y disimetrías entre unas y otras, tomamos como punto de partida la GV por ser la más antigua. Se compone de una guía descriptiva con una precisa organización textual que parte del epicentro, la Plaza del Castillo, el punto neurálgico de la ciudad, y se desglosa en los varios edificios de interés artístico, religioso y social, hasta llegar a la periferia del modo siguiente: 1) Establecimientos eclesiásticos (pp. 11-19); 2) Instrucción pública (pp. 19-67); 3) Beneficiencia y caridad (pp. 67-71); 4) Edificios públicos (pp.71-83); 5) Edificios militares (pp. 83-85); 6) Afueras de Pamplona (pp. 85-87). La GV se caracteriza por la amplitud informativa, ya que no se ha excluido de la descripción ningún edificio de los que existen en la ciudad. Con ello el emisor quiere dar una visión global de los aspectos históricos y socioculturales, que se traducen en una descripción minuciosa y ordenada del conjunto monumental en la que llega a reproducir los epitafios e inscripciones latinas, para facilitar al destinatario la lectura de los mismos. Ello nos da una idea del tipo de destinatario culto al que la guía se dirige y que mita, situada en un extremo de la ciudad, detrás del convento de los Descalzos, dedicada á [sic] una imagen muy antigua de piedra, que representa a la Virgen de la $\mathrm{O}$, y que, por el gran tamaño de dicha imagen, se la llama Santo Andía, que en vascuence significa Santo grande. Fué [sic] en lo antiguo hospital, a cargo de la cofradía de labradores del Burgo de San Cernín. La piedad generosa de un devoto de Pamplona ha fundado en esta ermita una capellanía para que se celebre todos los días del año una misa de alba, antes que la de las parroquias, con gran contentamiento de las pobres lavanderas (GV, p. 65).

En efecto, la GV enlaza con el modelo de guía histórico-descriptiva propia de finales del siglo XIX, pero muestra también los signos inconfundibles de la guía, como la organización visual del texto que, si bien carece de fotografías e imágenes, se funda, como apunta Santulli (2007: 98), en el uso de la tipografía, aprovechando las posibilidades que proporciona este código, lo que se traduce en el uso de la cursiva para marcar el elemento que se va a 
describir y que interrumpe la secuencia para encabezar la línea siguiente. El uso de la negrita está reservado para titular los capítulos. Asimismo, la alternancia de las diversas reproducciones latinas, que el emisor propone en la letra original, dinamizan la organización visual y motivan el interés del lector hacia los monumentos en los que aparecen. En conclusión, la tabla anterior nos muestra que la macroestructura del corpus presenta bastantes semejanzas, por lo que se refiere a los contenidos, a excepción de la GV en la que se ha focalizado el interés en la capital de Navarra, en detrimento del resto de la región. Predomina en todas ellas el elemento descriptivo, con un crescendo de la información práctica (medios de transporte, horarios, precios), que alcanza su mayor desarrollo en la guía de 1929, la más completa desde el punto de vista informativo $^{11}$. Asimismo, la descripción de los lugares va acompañada de imágenes y fotografías que permiten al lector, por lo menos en parte, hacerse una idea del lugar y de sus habitantes, y experimentar con el emisor sus propias sensaciones; salvo en la de 1904 y en pequeña medida en la GT, las dos restantes muestran abundancia de fotografías y mapas con los que el emisor cumple la función de orientar y trasladar al turista al lugar.

\section{Procedimientos descriptivos}

\section{Modalidades descriptivas}

Para Guido / López (1984: 76), la descripción es "el procedimiento literario que permite caracterizar un objeto, un paisaje, una persona, o una situación a través de la observación sensorial y de los datos que nos proporcionan las sensaciones internas". Así pues, el proceso descriptivo conlleva tres fases: en la primera, el emisor observa la realidad que lo circunda; en la segunda, selecciona los datos recogidos; y, en la tercera, organiza y compone. Como espectadores solo podemos analizar la fase compositiva que implica la selección previa del lenguaje para informar al lector de esa realidad, siguiendo un principio de objetividad, y persuadirlo de las bellezas de la misma, con el fin de llevarlo a una toma de decisión, que es la visita del lugar. Esta se lleva a cabo, en la guía turística que nos ocupa, por medio de recursos expresivos de la lengua literaria, como son la adjetivación, la comparación, la metáfora, etc. Por otra parte, como muy acertadamente subraya Calvi (2006: 83-84), existen diversas formas de describir el lugar turístico que están relacionadas con el punto de vista del descriptor y la técnica utilizada por este.

Efectivamente, en nuestro corpus se constata una gran variedad de modalidades descriptivas, que oscilan entre la descripción pura y la descripción enciclopédica. La primera responde a una idea de esencialidad que corresponde al criterio de objetividad, lo que conlleva la exclusión de todas las posibles valoraciones subjetivas que empañarían la verosimilitud de lo afirmado. Asimismo, según este criterio, la descripción ha de señalar tanto los aspectos positivos como negativos, y ello determina, como veremos, el uso de formas disfóricas ${ }^{12}$ cuando el descriptor lo considera necesario. El ejemplo más representativo de este criterio descriptivo es la GT, en la que predomina lo que podríamos definir un estilo telégrafico, tal y como lo entiende Santulli (2007, 102), esto es, un estilo caracterizado por la elipisis de verbos (ser, estar y tener), y en muchos casos, también de artículos, como podemos observar en los ejemplos siguientes:

El Archivo del Ayuntamiento; nutridísimo y de gran valía. Museo Sarasate: muy visitado. Piso segundo (GT, p. 20).

Esta descripción telegráfica se acentúa en los itinerarios, donde la depuración verbal alcanza su máxima expresión:

$\mathrm{Al}$ valle de la Ulzama (25 kilómetros).

Uno de los valles más poéticos de Navarra.

Puerto de Marcalain; vistas panorámicas; grandes bosques.

Auza, Lizaso, Ilarregui, pueblos pintorescos.

En Arraiz unión con la carretera a Bayona por Elizondo.

En todo el valle, muy buenas hospederías (GT, p. 30).

Esta tendencia a la descripción esencial, coadyuvada por una disposición fragmentada y yuxtapuesta de los enunciados, nos hace pensar en un destinatario interesado sobre todo en las informaciones prácticas, que se presentan en forma de enumeración. Cabe señalar que este tipo de descripción es coherente con lo afirmado por el emisor en la presentación de la guía:

No es nuestro propósito extendernos ampliamente en narraciones y citas históricas, por motivos del fin de nuestro trabajo, que no es otro, más que el de realizar orientaciones de cultura atrayente con el matiz ligero del ambiente actual [...] Para los que pasan por nuestra Navarra y sientan el ansia de conocer algo de su pasado, de su vida y de sus reliquias, es esta obrita: para los navarros entusiastas de sus antepasados, puede servir de guía que les lleve a desear unos mas profundos estudios de lo que fué [sic] y creó nuestro Reino (GT, pp. 7-8).

De estas palabras se desprende el objetivo de orientar con "matiz ligero", es decir, una descripción esencial con la intención de atraer al turista, por lo que presuponemos una selección de los lugares de visita obligada, con una información concisa de los acontecimientos. El segundo aspecto de la objetividad, es decir, el empleo de formas disfóricas, concierne tanto a esta guía como a las restantes del corpus, como veremos más adelante.

La segunda modalidad descriptiva es la que hallamos en el resto del corpus y responde al modelo de descripción técnica, tal y como la entiende Garzone (2008: 132), esto es, caracterizada por la amplitud informativa en la que predomina la claridad expositiva, la organización de la información y sobre todo la precisión en los detalles y datos 
(cifras, números, etc.). Obviamente, al tratarse de discurso turístico, es obligado destacar el recurso a la hipérbole. En los ejemplos siguientes se muestra el contraste entre unas guías y otras, por el modo de describir la situación geográfica de Pamplona, partiendo de la pura síntesis de la GT y concluyendo en el puro estilo literario de la GC:

Situación geográfica: $42^{\circ} 29$ N. $2^{\circ} 10$ (GT, p. 9).

La Ciudad de Pamplona, capital del antiguo reino de Navarra, cabeza de su merindad y de su Sede episcopal, se halla situada á[sic] los $42^{\circ}$ y 49 de latitud septentrional, y $2^{\circ} I^{\prime}$ de longitud oriental del Meridiano de Madrid [...] (GV, p. 7).

La Muy Noble, Muy Leal, Muy Heróica [sic] e Imperial Ciudad de Pamplona, está situada a 442 metros sobre el nivel del mar. Existe una diferencia cronométrica de ocho minutos de adelanto, respecto a la hora oficial de Madrid (GTN, p.16).

La situación es admirable; ha hecho la Naturaleza un gran plano, y lo ha circundado de montes; en medio de ese plano, sobre un pedestal formado por tres colinas vestidas de unos muros robustos, que los siglos han embellecido cubriéndolos de negrura y esmaltándolos de yedra, los bascones hicieron una ciudad (GC, p. 9).

Estas modalidades descriptivas son un reflejo de la visión personal del emisor, quien piensa en un determinado destinatario a la hora de realizar su tarea de descripción. En la GC, el destinatario es el participante en el Congreso de Estudios Vascos en Pamplona, por lo que el autor opta por un estilo literario con una finalidad subjetiva y expresiva, omitiendo la situación geográfica porque presupone que el destinatario pertenece a su entorno cognitivo. En este sentido, los prólogos resultan ser muy esclarecedores, porque anuncian lo que serán los contenidos de las guías. Por ejemplo, el emisor de la GC afirma lo siguiente:

Es imprescindible enlazar las noticias de nuestra vida pretérita, tan brillante, tan llena de poesía épica unas veces, apacible y suave otras, [...] con las satisfactorias realidades de nuestra existencia actual. [...] Por eso en las páginas que siguen [...] se incluyen referencias del pasado y del presente. Si con nuestro trabajo modestísimo hemos logrado despertar la curiosidad de quienes lleguen a Navarra con deseos de conocer su personalidad, de bucear en su alma para descubrir su carácter, de investigar su origen y seguir el desenvolvimiento de su existencia a través del tiempo, nos consideraremos pagados con largueza (GC, p. 7).

El emisor recurre a la "captatio benevolentiae", aquí y en otras ocasiones, consciente de estar dirigiéndose a un destinatario de nivel intelectual elevado, y subraya la importancia de destacar los hechos del pasado - de hecho completará las secciones narrativas con los llamados Apuntes históricos y Notas históricas ${ }^{13}$ - en correlación con el presente. Estas secciones se convierten en estrategias de persuasión para despertar el interés del congresis- ta-turista, para quien el emisor ha predispuesto unas páginas en blanco tituladas Notas, de modo que aquel pueda escribir sus propios apuntes de viaje.

En el prólogo de la GTN, sin embargo, no aparece ninguna declaración sobre los objetivos que se propone el autor con la guía, y se muestra más claramente la finalidad persuasiva con un título exhortativo en segunda persona que no deja lugar a dudas: "iiiVisitad Navarra y su capital Pamplona!!!”. A partir de ahí, el emisor prosigue citando todos los rasgos históricos, geográficos y artísticos; así como las informaciones generales de contenido práctico (estado de las carreteras, clima, etc.) que caracterizan la región y que la hacen única. El objetivo del emisor es el de presentar, a modo de resumen, todos los contenidos en los que luego profundizará, para atraer desde el principio a un gran número de destinarios:

Los que gustéis de bellezas naturales; los aficionados al estudio de pueblos que conserven en su más puro primitivismo el carácter racial de sus antepasados [...]. Los buscadores de costumbres e indumentarias antiquísimas y de bellas policromías, colmaréis vuestros deseos e inquietudes en este pueblo de recias tradiciones (GTN, p. 5).

El emisor resalta los caracteres identitarios de la región como punto de fuerza del atractivo turístico de la zona y como parte integrante del binomio tradición - modernidad, muy explotado en la promoción turística actual.

\section{Progresión temática}

La descripción comporta la elección y ordenamiento de las informaciones de modo que estas resulten comprensibles para el destinario, y así lo testifican las palabras del emisor:

Pero no amontonemos las cosas y digámoslas con orden (GC, p. 10).

El mismo emisor precisa más adelante el tipo de orden que tiene pensado:

Otras iglesias. Las mencionaremos en orden cronológico y brevemente (GC, p. 25).

En suma, este descriptor trata de dar forma a los datos de la observación que hasta ese momento son una mera enumeración, como en el caso de la GT, caracterizada, como se ha dicho, por el estilo telegráfico. La disposición de los contenidos refleja el modelo top-down, por el que se parte del centro neurálgico de la ciudad, esto es, la Catedral y el casco antiguo donde se hallan los edificios religiosos, para pasar posteriormente a la descripción de los edificios públicos. Y el mismo orden se lleva a cabo en la descripción de los pueblos y villas más significativos, desde el punto de vista artístico-monumental. La descripción paisajística se lleva a cabo posteriormente. Pero cabe decir que la organización no es la misma en todo el corpus: 
por ejemplo, en la GV el emisor parte de la Plaza del Castillo y las plazas circundantes para proseguir por la Catedral, mientras que para el emisor de la GC: "Es natural que, en primer término, hablemos de la Catedral" (p. 20), y ese orden es el adoptado por las otras dos guías.

Debiendo dar un juicio sobre el tipo de organización informativa llevado a cabo en estas guías, la GV, aunque carece de fotografías, es la que mejor interpreta la función orientadora del destinatario con precisas descripciones e indicaciones para que el lector pueda llevar a cabo la visita de forma ordenada:

Naves laterales. Están, como se ha dicho, divididas en capillas, y para proceder con orden empezaremos por la puerta del lado del Evangelio [...]. Sigue la ${ }^{14}$

Capilla de San Juan Bautista (GV, p. 24).

Como se desprende del ejemplo citado, las cursivas indican el nuevo objeto de la descripción y aparecen siempre encabezando la frase. Además, las cursivas marcan la separación entre una secuencia y otra, identificando inmediatamente la dirección que se ha de seguir gracias al uso de expresiones verbales: sigue después el crucero; viene después la puerta del claustro; a continuación está, etc. En definitiva, se toma de la mano al turista para conducirlo a través del lugar.

\section{Estrategias discursivas}

En el discurso turístico las descripciones de los lugares se realizan a través de enunciados definitorios por medio de los verbos ser o tener; mientras que los verbos estativos estar y hallarse quedan reservados para la localización del lugar, aunque el emisor recurre a veces a la elipsis. La definición sirve para determinar las características de una ciudad, un paisaje, un clima, o también un concepto o idea. La descripción comporta la sustracción del elemento descrito a su dimensión cronológica, reduciéndola a la dimensión temporal del emisor y del destinatario con el empleo del presente (Antelmi / Santulli 2007: 67):

Pamplona es la Capital del antiguo Reino Pirenáico [sic], hoy provincia de Navarra (GTN, p. 11).

Roncesvalles es un diminuto pueblo de siete casas agrupadas en derredor de la célebre Abadía o Real Colegiata considerada como uno de los más célebres Santuarios de la cristiandad (GTN, p. 47).

San Nicolás es un templo de transición del arte románico al ojival. [...] Tiene dos puertas antiguas: en la Plazuela y a la calle de San Miguel (GV, p. 25).

Es Estella un verdadero Museo de arte románico puro y en su transición al gótico primario (GTN, p. 144).

Puerta de "La Preciosa"; muy buena y de gran mérito, la mejor de toda la Catedral (GT, p. 15).

En otros casos, el emisor se sirve de formas impersonales y pasivas con el fin de cumplir con el principio de objetividad y, contemporáneamente, atenuar su impacto en el lector:
Al extremo del lado del Evangelio hay un altarcito llamado de Reyes, dedicado á [sic] la Santísima Virgen en el Descendimiento y coronado con el escudo real de España. [...] Pero la principal joya artística que hay que estudiar en el presbiterio es la verja central, que contemplan admirados los eruditos (GV p. 31).

Uno de los departamentos más curiosos del palacio era la Leonera,${ }^{15}$ donde se guardaban las muchas fieras que los Monarcas recibían como regalo, y alimentaban luego para distraerse contemplándolas (GC, p. 52).

[...] Antiguamente eran sepultados en esta cripta los Canónigos de esta Santa Iglesia. [...] (GV, p. 40).

Según los principios el discurso procedimental (Kerbrat-Orecchioni, 2004), hay también casos de despersonalización del discurso reservados para la descripción de los itinerarios, que reflejan las convenciones del género:

Se toma la carretera de la Avenida de Francia. A 5 kil. Villava, dejando la carretera de la derecha a Huarte y a Burguete se continúa por la que atraviesa la villa (GTN p. 38).

Asimismo, el emisor busca la objetividad a través de la intertextualidad, es decir, introduciendo textos de otros en forma de citas, fragmentos, comentarios, etc. que emplea como estrategia de verosimilitud y, por ende, persuasiva: a partir del referente por excelencia, Víctor Hugo y su obra Les Pyrenées ${ }^{16}$, a los que incluye en la guía como citas de autoridad (Montolío, 2000) ${ }^{17}$. El emisor, al describir un lugar que ha sido visitado por personajes ilustres, está llevando a cabo una estrategia persuasiva, apelando al ego del destinatario; máxime cuando dicho lugar ha servido a un artista o escritor de inspiración para su obra $^{18}$. Se trata de una estrategia que se sigue utilizando en las guías actuales:

A 2 kilómetros de Santesteban, Narvarte, centro de pesca de la trucha y el salmón, donde existe una magnífica Hostería de primer orden instalada en el Palacio de Reparacea, de la que era frecuente huésped el Rey Eduardo VII de Inglaterra y hoy frecuentada por selecta sociedad. En ella escribió su obra "La Marquesa Rosalinda” el novelista Valle Inclán (GTN, pp. 63-64).

Asimismo, puede ser una estrategia persuasiva en la descripción de un lugar, el que este fuera cuna de un personaje ilustre, ya que forma parte del entorno cognitivo del destinatario, como puede verse en el ejemplo siguiente:

Merece anotarse el detalle de que Estella es el pueblo en que nació el heróico [sic] capitán D. Julio Rodríguez Ruiz de Alda, tripulante - guía del "Plus Ultra" en el histórico vuelo España - Argentina (GT, p. 47).

Al lado de este regio salón, hállanse las habitaciones que ocupa S.M. el Rey, cuando visita Pamplona, siempre habilitadas y dispuestas" (GTN p. 31). 
Otras veces las citas de autoridad son las de los referentes extranjeros: "Con harta razón es calificado por las Guías extranjeras el bosque del Irati como uno de los más hermosos e imponentes de Europa" (GTN, p. 68).

Durante el proceso descriptivo, el emisor anticipa el pensamiento del destinatario y estimula su imaginación, introduciendo alguna digresión que dinamiza la descripción técnica de una obra de arte:

Cerca de esta Sala está una capillita que conserva columnas románicas y una reja sencilla, de gusto ojival. Acaso en esa capilla velaron los Reyes, según Fuero, en la noche anterior a su coronación, antes de que los ricos hombres les levantaran sobre el blasonado pavés [...] (GC, p. 23).

Pero la relación entre emisor y destinatario no se establece del mismo modo en todo el corpus. Ya hemos visto que en la GV se observa un uso de la impersonalidad para atenuar el impacto con el lector y mantenerlo a cierta distancia. En las otras guías, el emisor trata de involucrar al lector en la propia descripción u observación del lugar, a través del uso del "nosotros" participativo y el uso de la primera persona del plural con la modalidad exhortativa. Con ella, el emisor dinamiza el texto, creando en el receptor la ilusión de vivir la misma sensación:

Echemos una ojeada rápida por los monumentos arqueológicos de Sangüesa. Comenzaremos por la iglesia de Santa María (GC, p. 92).

Pero, otras veces, el emisor, opta por emplear el verbo describir + el 'nos' mayestático, de modo que cumple la función de organizador textual, dando inicio a una secuencia descriptiva:

Describámosla ligera y brevemente, comenzando por las construcciones de carácter religioso (GC, p. 37).

Se ha rastreado algún caso de apelación directa al lector en la segunda persona del singular:

Lector turista, si aún no has gustado del encanto y de la alegría de esta ciudad en plenos "Sanfermines" no dejes de hacerlo; es una recomendación especialísima [...] (GT, p. 33)

O en la segunda persona del plural, en el párrafo introductorio del prólogo de la GTN:

Los que gustéis de bellezas naturales; los aficionados al estudio de pueblos que conserven en su más puro primitivismo el carácter racial de sus antepasados, no deformado en sus esencias. [...] (GTN, p. 5).

\section{La selección léxica como procedimiento integrado en la descripción}

La descripción se lleva a cabo a partir de una selección léxica con la que el emisor del corpus intenta representar una imagen de Navarra $^{19}$ a sus posibles destinatarios. Esta operación discursiva se compone de dos mecanismos de persuasión; el primero responde al principio de credibilidad u objetividad, por el que se pretende convencer al lector de la verdad de lo dicho, y el segundo, intrínseco al proceso descriptivo, conlleva la adopción de formas evaluativas axiológicas, que contienen juicios de valor, o no axiológicas, en la terminología de Kerbrat-Orecchioni (1999: 100-112), para representar el lugar. La dificultad que puede entrañar este proceso se deduce de las palabras del emisor de la GC:

Jamás fuimos hiperbólicos y siempre vivimos dentro los susodichos muros ennegrecidos y cabe el hogar de nuestros padres. No hemos sentido el placer, un poco amargo, pero placer al fin, de la nostalgia que multiplica las bellezas del pueblo lejano. Así pues, en lo que hemos dicho, abonado en buena parte por un viajero sagaz y refinado - Víctor Hugo - y en lo que vamos a decir, no hay exageración (GC, p. 9).

El emisor justifica sus posibles desvíos hiperbólicos, tomando como referente la descripción del viaje de Víctor Hugo por los Pirineos. En esta, como en las restantes guías, la intertextualidad representa para el emisor la posibilidad de insertar puntos de vista que completan o corroboran sus aserciones. Se trata, en todo caso, de informaciones que remiten a conocimientos y creencias compartidos con el destinatario. Como recuerda Antelmi (2011: 78), "el objetivo es traer a la luz, mostrando sus posibles evoluciones, los esquemas de valoración, los temas recurrentes, los testimonios de una manera de pensar que se ha mantenido en el transcurso del tiempo". Con ello el emisor consigue un alto nivel de densidad informativa para satisfacer a su destinatario, con el que comparte el mismo saber enciclopédico.

Tanto en esta guía como en el resto del corpus el tema recurrente es la evocación de un pasado glorioso, la reafirmación de la propia identidad, el mantenimiento de la lengua, las tradiciones, el folklore y, por ende, la indignación manifiesta por el estado de abandono en el que se encuentran muchos monumentos que testifican dicho pasado. Este punto de vista es el que conduce al emisor a realizar una determinada selección léxica de sustantivos y adjetivos; y dentro de los adjetivos, la distinción se lleva a cabo entre los que se destinan para la descripción objetiva con valor denotativo y que se utilizan para la descripción subjetiva: evaluativos y afectivos por un lado, y evaluativos axiológicos y no axiológicos por otro.

Las formas no axiológicas son las que definen un objeto sin añadir un juicio de valor (sala espaciosa, salón capaz), mientras que las axiológicas emiten un juicio de valor positivo o negativo. Entras estas últimas se distin- 


\section{guen:}

- expresiones verbales con las que el emisor guía la atención del lector hacia un objeto o un lugar tanto en sentido positivo (es notable, tiene mérito, es de gran mérito, merece ser notado, merece especial mención, merece anotarse, etc.), como en negativo: (nada hay que merezca mención especial, no tiene ningún mérito);

- $\quad$ sustantivos como raza, país, lengua, tradición, folklore, reino, que transmiten determinadas creencias y valores;

- $\quad$ adjetivos que, como señala Maingueneau (2009), llevan implícita una carga de valor; el corpus muestra tanto adjetivos (admirable, apreciable, magnifico, precioso, soberbio, lindo, hermoso, airosisimo, etc.) como adverbios de modalidad (infelizmente, delicadamente, hermosamente, gallardamente, verdaderamente, admirablemente) y formas de participio (descaracterizado) para evaluar positiva o negativamente el objeto.

Todas ellas entran en el ámbito de la subjetividad o subjetivismo del que forman parte de manera especial los adjetivos. Las distintas formas evaluativas que aparecen en el corpus, constituyen un éthos ${ }^{20}$, es decir, por el contexto en el que son propuestos influyen en la construcción de un estereotipo privilegiado por la sociedad del tiempo. En el corpus que nos ocupa, destaca el nombre propio, porque puede poseer una gran carga semántica y evocadora de alto rendimiento pragmático, lo que es aprovechado por los autores de las guías, que lo convierten, así, en un verdadero anclaje del discurso:

A 2 kilómetros del Puerto, Roncesvalles: Su solo nombre remueve en el espíritu a aquellas grandes memorias de la jornada histórica que representa. En los abruptos y sombríos desfiladeros fueron recuperados Patria y libertad en una gesta gloriosa de la raza (GTN, p. 47).

Roncesvalles. El magnífico prestigio de este nombre sonoro y evocador, bastaría para despertar en el espíritu un anhelo ferviente de contemplar los estrechos desfiladeros que fueron teatro de una jornada histórica $[\ldots]$ (GC, p. 67).

La adjetivación apreciativa forma parte de lo que Calvi (2006: 59) denomina "palabras que se sitúan en el "área periférica del turismo" y que constituyen el ornatus del texto, gracias a la cual el emisor puede comunicar sus observaciones sensoriales al destinatario con el fin de apelarse a las suyas. Algunas de ellas revelan el punto de vista del emisor y dan lugar a estereotipaciones linguísticas, que son reflejo de estereotipaciones de pensamiento, y pueden representar polarizaciones axiológicas, como por ejemplo: antiguo y antiquísimo, adjetivos evocadores de un pasado glorioso (antiguo palacio, antigua iglesia) y moderno (o descaracterizado), evaluativo negativo por contraposición al anterior. En el caso que nos ocupa, estas polarizaciones axiológicas manifiestan, también, "la competencia cultural e ideológica del emisor" (KerbratOrecchioni, 1999: 106). Por ejemplo, en nuestro corpus, el emisor se muestra especialmente crítico con la urbanización moderna y con ciertas restauraciones del casco histórico, de ahí su connotación negativa, que puede verse intensificada por otros evaluativos negativos:

Flanquean la puerta, que es moderna y de ningún valor artístico, dos estribos puestos por ángulo, o sea dando al frente la arista (GV, p. 58).

En las calles de Jarauta, Chapitela, Estafeta y Zapatería están los ejemplares de ese tipo que el urbanismo moderno, ñoño y ridículo, aún no ha descaracterizado por completo [...] . Quedan casas señoriales del siglo $\mathrm{XVI}$, pero tan descaracterizadas unas y tan estropeadas otras, que difícilmente se las reconoce a simple vista (GC, p. 20).

Ahora bien, no faltan tampoco ejemplos de atenuación de los elementos disfóricos por medio del balanceo axiológico (Kerbrat-Orecchioni, 2004: 143), que el emisor utiliza para neutralizar un juicio de valor negativo, valiéndose del contraargumentativo pero:

Esbeltísima, aunque corta, de bóvedas sixpartitas, no es lo que fué [sic], pero sí es, aun con todo, la más hermosa de la ciudad, a pesar de sus deformaciones (GTN, p. 27).

Asimismo, los adjetivos seleccionados entran a formar parte de diversos enunciados comparativos y superlativos con los que el emisor manifiesta su compromiso afectivo, su punto de vista (Rebeyrolle, 2004: 180-1), lo cual se inscribe en el subjetivismo descriptivo anteriormente citado:

San Agustín: Parroquia del más moderno de los barrios pamploneses. Antiguamente perteneciente al Convento de Agustinos, convertido hoy en fábrica y en magnífico frontón de pelota (GTN, p. 29).

Entre las formas hiperbólicas destaca, por frecuencia de uso, el superlativo relativo, por cuanto posee una finalidad informativa de carácter referencial: debe mostrar (en relación con un punto de referencia) la ubicación que ocupa una magnitud en una escala (Gutiérrez Ordóñez, 2002: 82). De este modo, se confiere al objeto una posición jerárquica y una intensificación de la cualidad por el efecto acumulativo:

El interior del Coro es magnífico: consta de dos órdenes de sillas [...], están ejecutadas con tal mérito y exquisito gusto, que hacen de este coro uno de los mejores de España (GV, p. 32).

La Plaza de Abastos o del Mercado de Pamplona es una de las más hermosas y sobre todo mejor surtidas de España (GTN, p. 35).

Es asombroso el magnífico retablo del altar mayor, joya sin rival entre las más famosas colecciones de an- 
tigüedades del mundo. Es uno de los más bellos ejemplares de esmaltación incrustada de la Edad Media (GTN, p. 76).

Otro recurso para poner en relación diversos elementos descriptivos es la denominada "relación de analogía" (Adam, 2006), esto es, la puesta en relación de un lugar con otros con los que puede asimilarse por medio de comparaciones o metáforas:

San Pedro de la Rúa. Bellísima iglesia del siglo XII. Su fachada principal, transición de la arquitectura románica a la gótica, recuerda mucho las fachadas de las iglesias del Poitou (GTN, p. 145).

[...] La Basílica de Nuestra Señora de Eunate (en vascuence cien puertas) uno de los más curiosos monumentos de España, más notable quizá y muy semejante a la Iglesia circular de Zamarramala de Segovia [...] Muy pequeña esta iglesia, debido a que los Templarios no admitían al pueblo en sus ceremonias religiosas (GTN, pp. 152-153).

Ciertas comparaciones pueden llegar a formar clichés que se repiten en diversas guías, dando lugar a lo que Margarito (2004: 122) ha definido como "la pratique stéréotypée des stéréotypes". Precisamente, estas citas van adquiriendo con el tiempo el estatus de descripción con valor de autenticidad:

Ya hemos dicho que se ha llamado a Estella la Toledo navarra $^{21}$ (GC, p. 37).

Elizondo: Muy linda villa, Capital del Valle de Baztán, que por su belleza ha sido denominado "La Suiza Española" (GTN, p. 65).

Es un llano tan agradable por sus vistas, que Corella ha sido denominada la Andalucía navarra y digna también de compararse con una pintura de Flandes (GTN, p. 104).

Asimismo, el emisor se sirve del cliché: "Estella, la Toledo navarra", para dotar al texto de coherencia través de una serie de reiteraciones: Ya hemos dicho que se ha llamado a Estella la Toledo navarra (GC, p. 37), y a partir de ahí va desgranando las características que identifican una localidad con otra, como estrategia de justificación de lo anteriormente afirmado. La descripción de los monumentos religiosos prosigue con la de los civiles, para completar el sentido de lo afirmado en la comparación: $N_{o}$ son los monumentos religiosos únicos justificantes del apelativo toledano concedido a Estella (GC, p. 44).

La metáfora es otro recurso muy utilizado para destacar un lugar; guarda semejanzas con la comparación, pero posee, además, un poder evocador, ya que con ella se tiende a la poetización del discurso:

Numerosas y admirables son las excursiones que pueden realizarse por todo el territorio navarro "relicario perenne de un pasado asombroso" (GT, p. 29).

En la tabla siguiente se puede observar la mayor o menor frecuencia de uso de determinados adjetivos evaluativos positivos en las 4 guías. El vaciado de los mismos se ha llevado a cabo manualmente:

\begin{tabular}{|c|c|c|c|}
\hline GV (1904) & GC (1920) & GT (1926) & GTN (1929) \\
\hline $\begin{array}{l}\text { hermos* (10) } \\
\text { magnífic* (9) } \\
\text { sencill* (5) } \\
\text { modern* (5) } \\
\text { agradabl* (4) } \\
\text { elegant* (4) } \\
\text { exquisit* (4) }\end{array}$ & $\begin{array}{c}\text { interesant* (16) } \\
\text { antigu* (7) } \\
\text { bell* (5) } \\
\text { curios* (5) } \\
\text { espléndid* (4) } \\
\text { esbelt* (4) } \\
\text { modern* (4) } \\
\text { notabl* (4) }\end{array}$ & $\begin{array}{c}\text { admirabl* (20) } \\
\text { interesantísim* (8) } \\
\text { sum* (8) } \\
\text { estimabl* (5) } \\
\text { curiosísim* (4) } \\
\text { notabilísim* (4) }\end{array}$ & $\begin{array}{c}\text { notabl* (63) } \\
\text { magnífic* (41) } \\
\text { soberbi* (34) } \\
\text { bellísim* (31) } \\
\text { interesant* (29) } \\
\text { antiquísim* (23) } \\
\text { curios* (18) } \\
\text { encantador* (13) } \\
\text { notabilísim* (10) } \\
\text { admirabl* (10) } \\
\text { hermos* (10) } \\
\text { bell* (9) }\end{array}$ \\
\hline
\end{tabular}

Comparando unas guías con otras, se observan las distintas preferencias evaluativas de los autores, entre las que descuella la GC por la menor propensión a la encomiástica manifestada por el emisor, quien manifiesta su temor a ser tachado de hiperbólico, ya que se dirige a un destinatario muy culto. Dentro de las formas axiológicas más recurrentes del corpus, se han observado las siguientes colocaciones:

1) Adj. + sust y sust.+ adj.: curioso aljibe, salón suntuoso, suntuoso palacio, precioso mosaico, relicario de inestimable valor, verdes praderías, paisaje incomparable, recuerdo imperecedero, emociones imperecederas, frescas umbrias, pueblo pintoresco, ferias renombradas, curiosa tradición, esbeltas columna, etc.

2) Superlativos absolutos: itinerario bellísimo, paseo concurridísimo, curiosísima ceremonia, llanura fertilísima, afamadisima arquilla, tradición fundadísima, riquísimo paño de oro, etc.

3) Asociaciones bimembres (sust. y adjetivo; adj. y adverbio): rica y bien tallada, bonita y bien cuidada 
ciudad, severa y elegante portada románica, paisaje majestuoso y solemne, paisaje suave y risueño, característico y lindo pueblo, casas interesantes y curiosísimas, construcción vasta y sólida, etc.

4) Enumeraciones: edificio de sillería marmórea, ordinaria, casi negra; claustro frío, severo, casi tétrico; urbanismo ñoño, moderno y ridículo, etc.

La combinación de recursos lingüísticos y estrategias discursivas, junto con el componente visual formado por imágenes y fotografías, coadyuvan a la creación de un marco conceptual que se relaciona con un lugar determinado. Estas últimas forman parte de la operación descriptiva denominada "relación de contigüidad", que se establece, desde el punto de vista espacial, entre el texto descriptivo y las fotografías que ilustran el texto. En este sentido, las correspondientes a la GTN, son las más numerosas y adecuadas al texto escrito.

Dicha relación de contigüidad se lleva a cabo también desde el punto de vista temporal, esto es, ubicando el texto en un tiempo histórico o individual. En el corpus, las secuencias narrativas se hallan perfectamente entrelazadas con las descriptivas, por lo que no siempre son escindibles:

La Virgen del Sagrario. [...] Delante de esta Santa Imagen velaron sus armas y fueron consagrados nuestros monarcas; presidió ella las Cortes que se celebraron en Pamplona, y en su presencia se otorgaron todos los juramentos de los reyes y príncipes, aun después de la unión de Navarra á Castilla [...]. El tamaño de esta Santa Imagen es mitad del natural próximamente; su materia es una madera y muy dura; está sentada con el Niño Dios en su regazo, pero como superpuesto (GV, p. 42).

La narración de los hechos está fundamentada en el uso de determinados tiempos verbales, que corresponden a diferentes tipos de ubicación en relación con la posición del enunciador, y se reparten en diversos planos de enunciación (Adam, 2006: 74). Para narrar eventos históricos el emisor elige los tiempos verbales del pasado (en tercera persona del singular): pretérito imperfecto y pretérito indefinido, con los cuales marca la distancia hacia aquellos, pero alterna su uso con el presente cuando su objetivo es acercar al lector al escenario y hacerlo partícipe de lo comentado:

La romanización tuvo que dejar, necesariamente, sedimento civilizador que acaso perdurase en los primeros siglos medios, ya que los visigodos fueron aquí odiados y rechazados. Después el arte románico tuvo una manifestación espléndida, magnífica: la Catedral [...]. En el segundo periodo de la Edad Media los judíos tienen, también, aquí, su cultura; David Kimchi, en 1232, comenta la Biblia y escribe de gramática hebrea: Chayim Gallipapa es, en 1348, ritualista (GV, pp. 18-19). Existía antiguamente en Roncesvalles hospedería para los peregrinos que se trasladaban a Santiago de Compostela. Enfrente de la Abadía, la Capilla del
Sancti Spíritu [...]. En esta capilla, durante el mes de Mayo, se rezan sufragios por las almas de los muertos en la tremenda derrota de Carlomagno que según tradición, fueron en ella enterrados (GTN, p. 50).

En los albores de la monarquía navarra, Iñigo Jiménez Arista primer Rey indubitado escogió en el siglo IX para su residencia un antiguo y casi derruído Monasterio, el de Leyre. Lo reedificó y lo erizó de matacanes, torres, almenas y saeteras (GTN, p. 127).

Además de las ya citadas, otra forma verbal muy frecuente en la narración es el participio en construcción absoluta, con el que el emisor expresa cuándo, y a veces cómo y por qué ocurre el evento denotado por el predicado principal:

Ocupada por los árabes casi toda España, fueron desterrados de sus Sedes los Prelados que las gobernaban [...]. Seguían a la Corte siendo siempre Obispos de las Diócesis de que habían sido desposeídos hasta que las poblaciones capitales de sus Sedes eran reconquistadas por las fuerzas cristianas. Pasados los primeros años de la Reconquista, afianzados y ensanchados los nacientes Estados cristianos, pensaron los Reyes en fijar de modo permanente sus andariegas Cortes en lugares difícilmente asequibles a las invasiones árabes. Pensaron entonces también en crear Catedrales en los escondidos lugares que escogieron para su residencia, pues en aquella época, Religión, Patria y Monarquía formaban un todo orgánico (GTN, pp. 125-126).

\section{Conclusiones}

Al comenzar este trabajo, hemos partido de unos presupuestos sobre el tipo de representación que subyace al modelo textual descriptivo empleado en las guías turísticas de Navarra de 1904-1929, por parte del emisor de las mismas. El análisis textual del corpus viene a confirmar la existencia de un continuum entre el modelo textual histórico-descriptivo, característico de las guías publicadas en España a finales del siglo XIX, y los nuevos modelos que tienen también como referente la guía Baedecker de tipo objetivo y utilitario, y destinada a un turista de masa. Desde el punto de vista macroestructural, el corpus presenta algunas disimetrías entre la GV y las restantes guías por el contenido de las partes, que refleja el punto de vista del emisor y los objetivos que con ellas se propone. Existen también disimetrías que atañen al tipo de enunciado definitorio: en la GT se opta por un modelo descriptivo telegráfico y esencial, frente al modelo técnico caracterizado por la alta densidad informativa, que se halla presente en el resto del corpus.

En todas las guías (salvo en la GV) el emisor anuncia en el prólogo los propios objetivos de los cuales se desprende el tipo de destinatario al que se dirige la guía, y, por ende, el tipo de representación del lugar que pretende llevar a cabo. Cabe destacar, también, que la captación del destinatario no se realiza en todo el corpus con la mis- 
ma eficacia comunicativa: sobresale, en particular, la GC, que se orienta a un destinatario concreto, el congresista, por lo que emisor y receptor comparten el mismo saber enciclopédico.

Asimismo, el corpus muestra disimetrías en los mecanimos de persuasión adoptados; por ejemplo, la documentación visual inexistente en la GV, aparece paulatinamente en las restantes guías y alcanza su índice más alto en la GTN, que contiene una gran cantidad de fotos de paisajes, monumentos y de figuras humanas (estas últimas no aparecen en el resto del corpus).

El léxico desempeña una función relevante en la construcción de la imagen del lugar y por ello el emisor lleva a cabo una selección de sustantivos, adjetivos y expresiones verbales, cuya función es la de aportar una valoración objetiva, pero que acaban reflejando juicios de valor, precisamente por intentar ajustarse al principio de objetividad. Por esta razón, se rastrean elementos disfóricos, si bien la mayor parte de las veces acaban siendo atenuados por el emisor recurriendo al balanceo axiológico. Por otra parte, el uso reiterativo de determinadas comparaciones y colocaciones preanuncia la tendencia a la estereotipación en el discurso turístico. Asimismo, descuellan en el corpus determinados términos que remiten al patrimonio cultural (lengua, folklore, tradición, paisaje) y constituyen signos de identidad, que siguen utilizándose como mecanismos de persuasión en el discurso turístico actual. En definitiva, más allá de las diferencias observadas en el corpus, propias de la fase de asentamiento del género, este presenta una atención cada vez mayor por las líneas vectoras del discurso procedimental, que con mayor o menor coherencia recorren todo el corpus.

\section{Bibliografía}

Adam, Jean-Michel

2006 La linguistique textuelle. Introduction à l'analyse textuelle des discours. Paris: Colin.

Alcaraz-Varó, Enrique / Martínez Linares, María Antonia

2004 Diccionario de lingüística moderna. Barcelona: Ariel.

Amossy, Ruth / Herschberg Pierrot, Anne

1997 Stéréotypes et clichés. Langue, discours, société, Nathan, Paris.

Antelmi, Donella

2011 "Guías turísticas, intertextualidad y memoria discursiva: las Guías de Italia en lengua francesa”. En Calvi, M. V. / Mapelli, G. (Eds) La lengua del turismo. Géneros discursivos y terminología (pp. 75-92). Bern: Peter Lang.

Antelmi, Donella / Santulli, Francesca

2007 Pragmatica della comunicazione turistica. Roma: Editori Riuniti.

Araujo, Fernando

1884 La reina del Tórmes: guía histórica-descriptiva de la ciudad de Salamanca, Imp. y it. de Jacinto Hidalgo, $301 \mathrm{pp}$.
Baedeker, Karl

1913 Spain and Portugal. Handbook for travellers. Leipzig: Baedeker. http://sites.google.com. Consultado el 30/09/2010.

Bayón Mariné, Francisco / Fernández Fuster, Luis

1999 "Los orígenes". En Bayón MarinéP, F. et al. (Eds.), 50 años del Turismo español: un análisis histórico y estructural (pp. 25-45). Madrid: Editorial Universitaria Ramón Areces.

Bordonaba Zabalza, María Cristina

2011 "La comunicación turística en las páginas web de la Comunidad Foral de Navarra". En Bazzocchi, G. I Capanaga, P. / Piccioni, S. (Eds.), Turismo ed enogastronomia tra Italia e Spagna. Linguaggi e territori da esplorare (pp. 169-181). Milano: FrancoAngeli.

Calvi, Maria Vittoria

2006 Lengua y comunicación en el español del turismo. Madrid: Arco/Libros.

Calvi, Maria Vittoria

2010 "Los géneros discursivos en la lengua del turismo: una propuesta de clasificación”. Ibérica, 19: 9-32.

Calvi, Maria Vittoria / Mapelli, Giovanna (Eds.),

2011 La lengua del turismo. Géneros discursivos y terminología. Bern: Peter Lang.

Delmas, Juan

1864 Guía histórico-descriptiva del viajero en el Señorio de Vizcaya. Valladolid: Maxtor, 601 pp.

Ducrot, Oswald

1984 Le dire et le dit. Paris: Minuit.

Esteve Secall, Rafael / Fuentes García, Rafael

2000 Economía, historia e instituciones del turismo en España. Madrid: Pirámide.

Ford, Richard

1855 A handbook for travellers in Spain. London: Murray. http://archive.org. Consultado el 2.02.12.

Garzone, Giuliana

2008 "Promozione turistica e identità: il caso dei portali web in Italia e in Spagna”. En Calvi, M. V. / Mapelli, Giovanna / Santos López, Javier (Eds.), Lingue, culture, economia (pp. 121-145). Milano: FrancoAngeli.

Guía del congresista

1920 Pamplona, II Congreso de Estudios Vascos.

Guía del turista

1926 Pamplona, Imp. y Lib. de Vda de T. Bescansa.

Guía turística de Navarra

1929 Navarra: Comité Provincial de Exposiciones, con la cooperación de la Junta de Turismo y bajo el alto patrocinio de la Excma. Diputación Foral y Provincial de Navarra y el Excmo. Ayuntamiento de Pamplona, Aramburu, $214 \mathrm{pp}$.

Guía del viajero en Pamplona

1904 Madrid, Establecimiento tipográfico de Fortanet.

Guido, Rita Maria / López, Ana María

1984 Didáctica de la lengua. Argentina: El Ateneo.

Gutiérrez Ordóñez, Salvador

2002 Forma y sentido en sintaxis. Madrid: Arco/Libros.

Hugo, Victor

1991 I Pirenei. Torino: EDT. 
Kerbrat-Orecchioni, Catherine

1999 L'énonciation. Paris: Colin.

Kerbrat-Orecchioni, Catherine

2004 "Suivez la guide! Les modalités de l'invitation au voyage dans les guides touristiques: l'exemple de l'île d'Aphrodite". En Baider F. / Burger, M. / Goutsos D. (Eds.), La communication touristique. Approches discursives de l'identité et de l'altérité / Tourist Communication. Discursive Approach to Identity and Otherness (pp. 133-150). L'Harmattan, Paris.

Maingueneau, Dominique

1984 Genèses du discourse. Liège: Mardaga.

Maingueneau, Dominique

1987 Nouvelles Tendances en analyse du discourse. Paris: Hachette.

Maingueneau, Dominique

1999 "Ethos, scénographie, incorporation", (pp. 75-100) En Amossy, R. (Coord.) /Images de soi dans les discours. La construction de l'ethos,/ Paris: Delachaux et Niestlé.

Maingueneau, Dominique

2009 Les termes clés de l'analyse du discours. Paris: Seuil. Margarito, Mariagrazia

2004 "Quelques configurations des stéréotypes dans les texts touristiques". En Baider, F. / Burger, M. / Goutsos, D. (Eds.), La communication touristique. Approches discursives de l'identité et de l'altérité / Tourist Communication. Discursive Approach to Identity and Otherness (pp. 117-132). L'Harmattan: Paris.

Montolío, Estrella

2000 Manual de escritura académica. Barcelona: Ariel.

Rebeyrolle, Josette

2004 "L'acte définitoire dans les guides touristiques". En Baider, F. / Burger, M. / Goutsos, D. (Eds.), La communication touristique. Approches discursives de l'identité et de l'altérité / Tourist Communication. Discursive Approach to Identity and Otherness (pp. 173-190). L'Harmattan: Paris.

Ruiz Dávila, Deyanira

La descripción, una operación discursiva, (http://www. uv.mx) (Consultado el 31/07/2011).

Santulli. Francesca

2010, "Dall' illic et tunc all'eterno presente: trasformazione delle strutture enunciative per la nascita di un nuovo genere testuale". En Canals, J. / Liverani, E. (Eds.), Viaggiare con la parola (pp. 103-119). Milano: Franco Angeli.

\section{Notas}

1 Se llevan a cabo las Exposiciones Universales de Barcelona y Sevilla, y se crea el Patronato Nacional de Turismo (PNT). También se realiza la Exposición de España en Nueva York de 1922-23, a la que sigue la Exposición Obras del Turismo en España, en Filadelfia (Bayón, 1999: 30). Asimismo, junto a la construcción de hoteles para el turismo de lujo, que se llevó a cabo tras la primera guerra mundial, la Comisión Regia para el Turismo creó un conjunto de hoteles destinados a la clase media, siguiendo el modelo de las misiones españolas en California, que conducirían a la construcción de los primeros Paradores Nacionales. El Directorio de Primo de Rivera prestó atención al turismo, ya que por el Real Decreto 745/1928 de 25 de abril, creó el Patronato Nacional de Turismo, que absorbería todas las funciones de la Comisaría Regia de Turismo (CRT). En la exposición de motivos, el turismo aparece definido como "fuente de riqueza", ello representa una real novedad, ya que hasta entonces no se había enfocado el turismo desde esa perspectiva, y como "fuente de prestigio nacional"; es decir, enmarcado en una perspectiva nacionalista muy propia de la época" [...].(Esteve / Fuentes, 2000: 18-24).

2 Entre otras, la Guía histórico-descriptiva del viajero en el Señorío de Vizcaya de Juan Delmas (1864), La reina del Tórmes. Guía histórico-descriptiva de Salamanca (1884).

3 Así lo atestigua José María de Areilza en el prólogo a la segunda edición de la Guía histórico-descriptiva del viajero en el Señorío de Vizcaya de Juan Delmas (1864), donde se documenta también la existencia de otras guías de la época, fruto de la labor conjunta de varios literatos.

4 John Murray (1808-1892), en 1836, empezó su famosa serie de guías llamadas Murray's Handbooks o, más conocidas como Murray's Red Guides, por las tapas de color rojo, que se inspiraban en las de las de la Biblia, para todos los países que eran la meta del Gran Tour. Estas guías representaron el punto de partida de las Baedeker pero, a diferencia de estas últimas, no fueron traducidas a otros idiomas. La guía dedicada a España, A handbook for travellers in Spain (1855, $3^{a}$ edición), contiene en su página de presentación, a modo de síntesis, la frase en español, "Quien dice España-dice todo".

$5 \quad$ La traducción es mía.

6 De ahora en adelante GV.

7 De ahora en adelante GC. Esta guía fue publicada con ocasión del II Congreso de Estudios Vascos que tuvo lugar en Pamplona.

8 De ahora en adelante GT.

9 De ahora en adelante GTN.

10 Estos capítulos contienen información sobre los centros de enseñanza, los conventos, el cementerio, los hospitales o los cuarteles, edificios que para los autores de las guías no forman parte del itinerario turístico habitual.

11 En la guía GTN, de 1929, se incluye todo tipo de información detallada sobre las distancias kilométricas, los horarios de todos los trenes y autobuses con los precios de cada uno de ellos e incluso las partituras de algunas canciones populares. Asimismo, el autor facilita la consulta de los itinerarios ya des- 
critos en el interior de la guía, añadiendo unas "Advertencias" al final del libro, con las que sugiere otros itinerarios personalizados para las visitas breves, es decir, el tipo de itinerario que equivale al hodierno de "fin de semana".

12 Las formas disfóricas son expresiones evalutivas (no merece la pena, no hay nada digno de mención, está desescaracterizado, etc.), que los autores de las guías emplean, para señalar al lector los objetos o lugares que no merecen ser visitados.

13 Como señala Santulli (2010), las guías contienen de forma explícita o no explícita informaciones históricas que aparecen desarrolladas con diversos grados de profundización; en la GC el emisor ha destinado el apartado Apuntes históricos al final del capítulo (p. 78-80) y Notas históricas al principio del mismo (p. 31), tal y como anuncia en la cita siguiente: "cuanto llevamos dicho, serán unos apuntes históricos sobre el antiguo cenobio de San Salvador de Ibañeta" (GC, p. 78).

14 Hemos respetado la disposición textual de los enunciados en el texto.

15 La cursiva no es mía.

16 El emisor alude a la descripción hecha por Victor Hugo de la ciudad de Pamplona y, en concreto, de la Catedral, en su libro de viajes, En voyage Alpes et Pirenées. En la edición italiana, Victor Hugo, I Pirenei, Torino, EDT, 1991, pp. 109-138.

17 Nos referimos a las citas de eruditos y a las notas a pie de página que son frecuentes en la GT, de este modo el autor proporciona al lector la bibliografía necesaria en caso de que quiera completar la información. Pero también son frecuentes en el resto del corpus.

18 Como en la GV, cuyo autor describe, con las palabras de Bécquer, el efecto que la visión de la Cruz de los peregrinos le produjo y que se convirtió en fuente de inspiración para su obra (GV, p. 77-78). En la GTN, el autor cita en varias ocasiones la obra Amaya o los vascos en el siglo VIII, porque en ella aparecen descritos varios paisajes que el mismo señala en su guía.

19 Sobresale, en este sentido, la GTN, porque en sus páginas el emisor destaca con énfasis las raíces vascas de Navarra como signo de identidad y de atracción turística (raza, país, patria, folklore vascongado, etc.). Los culturemas, presentes en dicha guía (mutil-dantza, soka-dantza, etc.) y acompañados de las correspondientes fotografías, son arquetipos de un mundo, de una realidad desconocida que se ofrece al lector para ayudarlo en la identificación del lugar o del objeto, una vez que se encuentre en el lugar descrito.

20 Véase Ducrot (1984); Amossy (1999); Maingueneau (1984, 1987, 2002)

21 Con una ligera variante "Estella, la Toledo del norte", este cliché se sigue empleando en la actualidad, tal y como se ha constatado en el sitio web de la Comunidad Foral de Navarra (Bordonaba, 2011: 175).
Recibido:

Reenviado: Aceptado:

$8 / 2 / 2012$

$26 / 3 / 2012$

$10 / 4 / 2012$ 